\title{
Sensitivity Analysis of Different Capacity Spectrum Approaches to Assumptions in the Modeling, Capacity and Demand Representations
}

\author{
Tiziana Rossetto ${ }^{1}$, Pierre Gehl ${ }^{2}$, Stylianos Minas ${ }^{1}$, Arash Nassirpour ${ }^{1}$, \\ Joshua Macabuag $^{1}$, Philippe Duffour ${ }^{1}$, John Douglas ${ }^{2}$
}

\author{
${ }^{1}$ EPICentre, Dept. of Civil, Environmental and Geomatic Engineering, University \\ College London, Gower Street, London, UK; email: t.rossetto@ucl.ac.uk \\ ${ }^{2}$ Risks and Prevention Division, BRGM, 3 avenue Claude Guillemin, 45060 Orléans, \\ France
}

\begin{abstract}
Several capacity spectrum assessment methods exist for determination of structural performance of building models subjected to earthquake loading. The repetition of such analysis for earthquakes of increasing intensity will result in the derivation of analytical fragility functions. A comparison of three capacity spectrum assessment approaches (N2, SPO2IDA and FRACAS) has been carried out, highlighting the advantages and limitations of the approaches. Two experimental case studies have been chosen to evaluate the IM-EDP $\left(\mathrm{S}_{\mathrm{a}}-\mathrm{S}_{\mathrm{d}}, \mathrm{ISD}_{\max \%}\right)$ estimates obtained from the three different capacity spectrum procedures as well as from non-linear time-history analyses (NLTHA). It is found that all three approaches perform well in estimating the response of a simple steel frame but that FRACAS provides the best estimate of the response of an irregular reinforced concrete frame. It is concluded that further comparisons of the capacity spectrum approaches with large-scale experiments on structures are required to draw more general conclusions.
\end{abstract}

\section{INTRODUCTION}

In the construction of analytical fragility functions multiple structural models need to be analysed numerous times under earthquakes of increasing intensity, resulting in thousands of runs. These are required to appropriately account for the natural variation between structures within a building class, and the variability in the seismic excitation (e.g. earthquakes of the same magnitude at the same distance may induce different ground accelerations at a given site). To date, the computational expense involved typically precludes the use of non-linear dynamic time history analysis (NLTHA) of 3D structural models. Hence, for the practical generation of analytical fragility functions, many variants of capacity spectrum assessment have been proposed that are either based on incremental dynamic analyses (IDA) or static pushover analyses (PO) such as SPO2IDA (Vamvatsikos \& Cornell, 2006), N2 (Fajfar, 2000) and FRACAS (based on Rossetto \& Elnashai, 2005). These methods compare a static representation of the structural response to that of earthquake demand so as to determine the resulting Engineering Demand Parameters (EDPs) corresponding to a given Intensity Measure (IM). In doing this, the methods make several simplifying assumptions in the structural modelling, structural capacity 
representation, number of earthquake records used and the method for representing and scaling the seismic demand. Despite the existence of several approaches, they have not been compared in any systematic way nor (for the most part) have they been tested against large-scale experimental data of buildings subjected the earthquake excitation. Hence, the effects of modelling and capacity assessment assumptions on the uncertainty in the resulting EDPs and fragility curves have not been appropriately determined.

This paper presents a first step towards assessing the sensitivity of EDPs to assumptions made in the modelling, capacity and demand representation. It presents a comparison of structural response parameters predicted by the three aforementioned capacity spectrum assessment approaches and by non-linear time history analyses (NLTHA), with the published results of full-scale experiments of a four-storey reinforced-concrete bare frame tested pseudo-dynamically and a twostorey steel frame tested on a shaking table.

\section{COMPARED APPROACHES}

In this paper the SPO2IDA, N2 and FRACAS capacity spectrum approaches are compared to the results of NLTHA and published experimental data for two case study structures.

The N2 Method is based on work of Fajfar (2000), which has also been recommended approach by Eurocode 8 (CEN, 2004). The process is specifically applicable to structures that can be characterised by a bilinear elasto-perfectly plastic (EPP) capacity curve. The method uses the pushover analysis of a multi degree of freedom (MDoF) model to define an equivalent single-degree-of-freedom (SDoF) system that is in turn used to define a capacity curve of EPP shape. Inelastic demand spectra are determined from a typical smooth elastic design spectrum by applying the reduction factor, $\mathrm{R} \mu$. According to Faella et al. (2008), the method can be expanded and utilise response spectra directly derived from recorded accelerograms. The target displacement is obtained from the intersection of seismic demand and structural capacity curve.

SPO2IDA is a parametric analysis method proposed by Vamvatsikos \& Cornell (2006). SPO2IDA essentially adopts the capacity curve resultant of static pushover (SPO) to define the backbone curve of an equivalent SDoF. The collapse probability of the structure is then determined by drawing on a database of results from a large number of incremental dynamic analyses (IDA, Vamvatsikos \& Cornell 2002) previously carried out on a number of SDoFs subjected to 60 earthquake time histories. The latter SDoFs oscillators have a wide range of periods and backbone curves (from simple bilinear to complex quadrilinear with an elastic, hardening and softening segment, with some also featuring pinching hysteresis). However, it is worth mentioning that the earthquake input cannot be altered. This makes it impossible to modify the approach to, for example, assess structures under a single earthquake record. This method is recommended in ATC-58 (FEMA P-58, 2012). 
Both mentioned approaches are able to provide ISD values and fragility functions through back calculation of drifts from the performance point and appropriate statistical modelling methods and assumptions (D'Ayala et al., 2013).

FRACAS (FRAgility from CApacity Spectrum assessment) is based on the method proposed by Rossetto (2004) and Rossetto \& Elnashai (2005) for derivation of analytical displacement-based vulnerability curves. The procedure is described in detail in Gehl et al. (2014). In FRACAS the input capacity curve is idealised into a selected simplified curve and is cut into a number of points (checking points) at which the capacity and demand are compared. The demand is calculated by carrying out a NLTHA on a non-linear SDOF specified for the checking point, with the characteristics of the capacity curve shape up to the checking point defining the elastic period and ductility of the SDOF. The performance point is determined when the demand and capacity are the same at a checking point. The top drift and maximum interstorey drift ratio ( $\mathrm{ISD}_{\max \%}$ ) response of the structure is determined at the performance point from the results of pushover analysis, and are used to determine the damage state of the building. In contrast to the other two approaches, FRACAS has the advantage of permitting the use of various natural accelerograms that generate unsmoothed spectra as opposed to standardized design spectra. Furthermore, the approach allows for capacity spectra to be derived from both conventional and adaptive pushover analysis (APO), and the capacity curve to be idealised either as elastic perfectly-plastic (EPP), elastic with strain hardening post yield (EST) or as a tri-linear, non-degrading, curve (MML). Furthermore, it gives user the opportunity to automatically generate fragility curves based on the resulting EDP output. FRACAS is one of the methods recommended in the new GEM Guidelines for Analytical Vulnerability Estimation, (D'Ayala et al. 2014). Table 1 presents a comparison of the main features of the three approaches with NLTHA. Furthermore, Table 2 presents a summary of the Author's perceived strengths and limitations of the three approaches.

Table 1.Comparison of NLTHA with N2, SPO2IDA and FRACAS

\begin{tabular}{|c|c|c|c|c|c|c|}
\hline Approach & EDP & $\begin{array}{c}\text { Struct. Model } \\
\text { Idealisation }\end{array}$ & $\begin{array}{c}\text { Capacity } \\
\text { Input }\end{array}$ & $\begin{array}{l}\text { Demand } \\
\text { Input }\end{array}$ & $\begin{array}{l}\text { Direct } \\
\text { Output }\end{array}$ & $\begin{array}{c}\text { Indirect**: } \\
\text { Output }\end{array}$ \\
\hline$N 2$ & $\begin{array}{l}\text { Top } \\
\text { Drift }\end{array}$ & $\begin{array}{c}\text { SDoF } \\
\text { with EPP }\end{array}$ & $\begin{array}{l}\text { Conv. } \\
\mathrm{PO} / \\
\mathrm{APO}\end{array}$ & $\begin{array}{l}\text { Response } \\
\text { Spectra }\end{array}$ & $\mathrm{PP}^{*}$ & $\begin{array}{c}\left(\text { ISD }_{\max }\right) \\
\text { Fragility } \\
\text { Curve }\end{array}$ \\
\hline SPO2IDA & $\begin{array}{l}\text { Top } \\
\text { Drift }\end{array}$ & $\begin{array}{c}\text { SDoF } \\
\text { with MML } \\
\text { (User Def. } \\
\text { quadrilinear) } \\
\end{array}$ & $\begin{array}{l}\text { Conv. } \\
\mathrm{PO} / \\
\mathrm{APO}\end{array}$ & $\begin{array}{l}\text { Predefined } \\
\text { suites of } \\
\text { records }\end{array}$ & Collapse state & $\begin{array}{c}\left(\mathrm{ISD}_{\max }\right) \\
\text { Fragility } \\
\text { Curve }\end{array}$ \\
\hline FRACAS & $\begin{array}{l}\text { Top } \\
\text { Drift, } \\
\text { ISD }_{\max }\end{array}$ & $\begin{array}{c}\text { SDoF } \\
\text { with EPP, } \\
\text { EST, MML } \\
\text { (User Def. } \\
\text { trilinear) }\end{array}$ & $\begin{array}{c}\text { Conv. } \\
\mathrm{PO} / \\
\mathrm{APO}\end{array}$ & $\begin{array}{l}\text { A single or } \\
\text { series of } \\
\text { records }\end{array}$ & $\begin{array}{c}\mathrm{PP}^{*} \\
\left(\mathrm{ISD}_{\max }\right) \\
\text { Fragility Curve, } \\
\text { Conf. bounds }\end{array}$ & - \\
\hline NLTHA & $\begin{array}{l}\text { Various } \\
\text { EDPs }\end{array}$ & - & - & $\begin{array}{l}\text { A single or } \\
\text { series of } \\
\text { records }\end{array}$ & $\begin{array}{l}\text { EDP time } \\
\text { histories }\end{array}$ & $\begin{array}{l}\text { Fragility } \\
\text { Curve }\end{array}$ \\
\hline
\end{tabular}

*PP $=$ Performance Point ** some basic calculations required based on direct output 
Table 2.Strengths and Limitations of N2, SPO2IDA and FRACAS

\begin{tabular}{|c|c|c|}
\hline & Strengths & Limitations \\
\hline Z̃ & $\begin{array}{l}\text { - Easy to use and fast } \\
\text { - Minimum computational effort } \\
\text { - Recommended by Eurocode } 8 \\
\text { - User defined damage states } \\
\text { - Uses response spectrum derived either from } \\
\text { code (EC8) or ground motions (Faella et al. } \\
\text { (2008) as the demand input } \\
\text { - Can be extended to take into account higher } \\
\text { mode effects } \\
\text { - ISD and other EDPs can be calculated from } \\
\text { PP information and original PO curves } \\
\text { - Fragility curves can be generated with } \\
\text { appropriate assumptions }\end{array}$ & $\begin{array}{l}\text { - Poor representation of } \\
\text { structural characteristics (storey } \\
\text { mass and height of each floor) } \\
\text { - Poor representation of capacity } \\
\text { idealisation (restricted to } \\
\text { Elastic Perfectly Plastic) } \\
\text { - Uses code spectrum as demand } \\
\text { input }\end{array}$ \\
\hline & $\begin{array}{l}\text { - Easy to use and fast } \\
\text { - Minimum computational effort } \\
\text { - Good representation of the idealised } \\
\text { capacity curve (quadrilinear) } \\
\text { - Recommended by ATC-58 } \\
\text { - Applicable to infilled structures } \\
\text { - ISD and other EDPs can be calculated from } \\
\text { PP information and original PO curves } \\
\text { - Collapse fragility curve can be generated } \\
\text { with appropriate assumptions }\end{array}$ & $\begin{array}{l}\text { - Restrictions on choosing the } \\
\text { seismic input } \\
\text { - All fragility curves resulting } \\
\text { from SPO2IDA are for collapse } \\
\text { state } \\
\text { - Poor representation of } \\
\text { structural characteristics (storey } \\
\text { mass and height of each floor) }\end{array}$ \\
\hline$\sum_{\substack{\infty\\
}}^{\infty}$ & $\begin{array}{l}\text { - Capable of analysing multiple buildings } \\
\text { subjected to series of earthquake records } \\
\text { (scaled or unscaled) } \\
\text { - Good representation of building } \\
\text { characteristics (accounting for each storey } \\
\text { mass and height) } \\
\text { - Automatic generation of analytical fragility } \\
\text { curves based on user-defined damage states } \\
\text { - Fully customisable idealisation curve (EPP, } \\
\text { EST, MML, Usr Def.) } \\
\text { - Direct estimation of ISD } \text { max }_{\text {ax }} \text { at each } \\
\text { performance point }\end{array}$ & $\begin{array}{l}\text { - Higher computational effort } \\
\text { with respect to SPO2IDA and } \\
\text { N2 }\end{array}$ \\
\hline
\end{tabular}

\section{CASE STUDY BUILDINGS}

In this paper the published results of large-scale experiments on two structures are used to provide a benchmark against which to compare the capacity spectrum and NLTHA assessment approaches. The first case study is the shaking-table test of a two-storey, one bay, steel bare frame reported in Kim et al. (2006). This frame was subjected to the Loma Prieta record (PEER Strong Motion Database, Station: 47125 / CAP000). This model was chosen as it represents a simple regular structural frame. In order to account for a more complicated irregular arrangement and failure mode, a 
four-storey, three-bay, bare RC moment resisting frame (MRF), representing a typical non-seismically designed building of the European stock, was selected. This full scale model was tested pseudo-dynamically under artificial records representing earthquakes with a 475 and 975 year return period, at the ELSA Laboratory in Ispra as part of the ICONS project (Campos-Costa \& Pinto, 1997; Pinto et al. 1999; Carvalho et al. 1999).

\section{RESULTS}

A finite element model of each case study building is developed employing SeismoStruct software (SeismoSoft, 2007). The corresponding pushover curves for conventional (uniform and triangular force distributions) and adaptive approaches (ISD- Force- and Displacement- based scaling, Pinho \& Antoniou, 2005) are shown in Figure 1, together with the results of an incremental NLTHA and the reported experimental responses. It is observed that the experimental point (maximum roof drift ratio and base shear) lies close to all the pushover curves, and that these are of similar shape.

For both Steel and RC case studies, the PO curves along with structural characteristics and seismic demand were implemented as an input for the studied simplified capacity spectrum approaches. In the case of N2, an elastic spectrum replicating the applied earthquake record has been employed considering a highly seismic region with soil type B (EC8). The resulting values of Spectral Acceleration $\left(S_{\mathrm{a}}\right)$, Spectral Displacement $\left(\mathrm{S}_{\mathrm{d}}\right)$ and maximum interstorey drift ratio (ISD $\left.\mathrm{Imax}\right)$ obtained at the performance points are presented in Tables 3 to 6 . The results of NLTHA of the structural models subjected to the applied ground motions are also presented, together with the error between each assessment method and both the reported experimental structural response, and that estimated by NLTHA (presented in brackets).
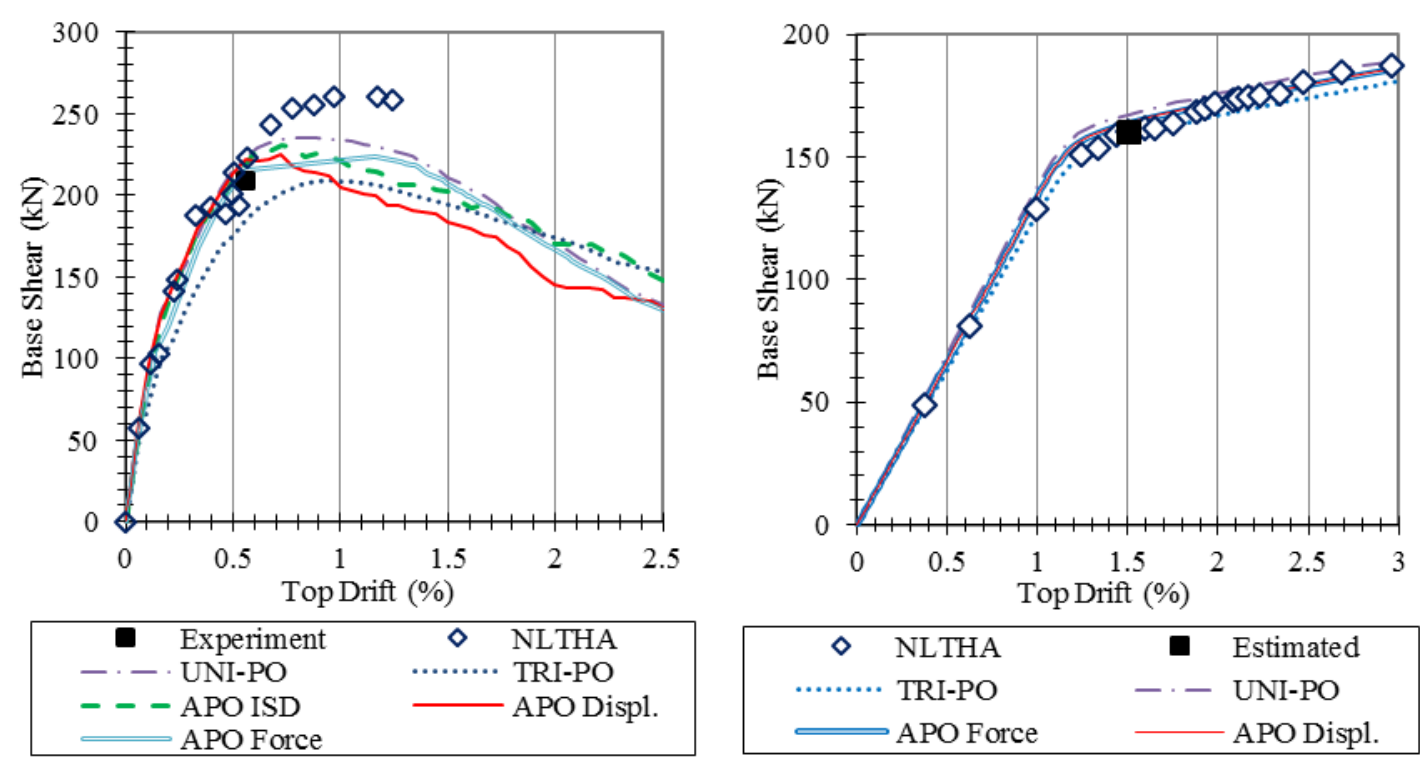

Figure 1.Comparison of different capacity curves with NLTHA and Experiment for RC bare Frame (left) and Steel building (right) 
In the case of both structures, the $\mathrm{N} 2$ method and FRACAS provide estimates of $\mathrm{S}_{\mathrm{a}}$ at the performance point that are almost all within $10 \%$ of the experiment results, and in the case of the steel building are within the range of error of that NLTHA estimates have with the experiments. In the case of $S_{d}$, the $\mathrm{N} 2$ estimate for the steel structure is comparable to that of NLTHA, as is the $S_{d}$ value for FRACAS in the case of a Uniform pushover and EPP idealization of the capacity curve. The latter also results in an estimate of ISD $_{\max }$ that is better than the estimate provided by NLTHA. However, for the RC frame, FRACAS provides better estimates of $S_{d}$ than N2 as compared to the experiments, and overall provides close estimates of the ISD $_{\max }$. Nevertheless, some of the combinations of pushover type with the MML idealization of the capacity curve (particularly for the steel structure), result in high errors (over $10 \%$ ) for both $\mathrm{S}_{\mathrm{d}}$ and $\mathrm{ISD}_{\max }$. The choice of idealization model for the capacity curve clearly has a significant effect on the results of the capacity spectrum assessment and needs further investigation in order for guidance to be produced as to which idealization model should be used for which structure type. All combinations with EPP and EST, however, here result in reasonably low errors.

SPO2IDA is a tool that can be used to estimate the collapse state and is not intended to predict the behaviour of the structure under a given seismic excitation. Hence, in order to be able to make a comparison for SPO2IDA with the experiments here, the $S_{a}$ value from the experiment is used, and only the resulting $S_{d}$ is assessed from the SPO2IDA results. In the case of $S_{d}$, all the results obtained from SPO2IDA perform slightly worse than N2 and the better FRACAS PO-idealisation model combinations.

Table 3.Comparison of responses predicted by NLTHA, SPO2IDA and N2 with the steel building experiment

\begin{tabular}{cccccccc}
\hline $\begin{array}{c}\text { Analysis } \\
\text { Methods }\end{array}$ & $\begin{array}{c}\mathbf{S}_{\mathbf{a}} \\
\left(\mathrm{m} / \mathrm{s}^{2}\right)\end{array}$ & $\begin{array}{c}\text { Error** } \\
(\%)\end{array}$ & $\begin{array}{c}\mathbf{S}_{\mathbf{d}} \\
(\mathrm{cm})\end{array}$ & $\begin{array}{c}\text { Error } \\
(\%)\end{array}$ & $\begin{array}{c}\text { ISD }_{\text {max }} \\
(\%)\end{array}$ & $\begin{array}{c}\text { Error } \\
(\%)\end{array}$ \\
\hline Experiment & - & 14.52 & - & 5.68 & - & 1.61 & - \\
\hline $\boldsymbol{N L T H A}$ & - & 16.34 & 12.6 & 5.58 & -1.8 & 1.68 & 4.4 \\
\hline \multirow{S}{\text{SPO2IDA}}{} & Uni & $14.52 *$ & - & 4.86 & $-14.3(-12.8)$ & 1.49 & $-7.5(-11.3)$ \\
\cline { 2 - 8 }$(50 \%)$ & Tri & 14.52 & - & 5.32 & $-6.3(-4.7)$ & 1.57 & $-2.5(-6.5)$ \\
\hline \multirow{2}{*}{$\boldsymbol{N} \mathbf{2}$} & Uni & 14.85 & $2.3(-9.2)$ & 5.70 & $0.4(2.2)$ & 1.81 & $12.4(7.7)$ \\
& Tri & 14.83 & $2.2(-9.3)$ & 5.87 & $3.3(5.2)$ & 1.75 & $8.7(4.2)$ \\
\hline
\end{tabular}

* The $\mathrm{S}_{\mathrm{a}}$ value used for SPO2IDA corresponds to the value obtained from the performance point of the experiment. ** Error with respect to the experiment is unbracketed, and error with respect to NLTHA prediction is provided in brackets. 
Table 4.Comparison of responses predicted by FRACAS using several pushover curves and capacity curve idealisations, with the steel building experiment

\begin{tabular}{|c|c|c|c|c|c|c|}
\hline $\begin{array}{l}\text { Analysis } \\
\text { Methods }\end{array}$ & $\begin{array}{c}\mathbf{S}_{\mathbf{a}} \\
\left(\mathrm{m} / \mathrm{s}^{2}\right)\end{array}$ & $\begin{array}{c}\text { Error* } \\
(\%)\end{array}$ & $\begin{array}{c}\mathbf{S}_{\mathbf{d}} \\
(\mathrm{cm})\end{array}$ & $\begin{array}{c}\text { Error } \\
(\%)\end{array}$ & $\begin{array}{c}\text { ISD }_{\max } \\
(\%)\end{array}$ & $\begin{array}{c}\text { Error } \\
(\%)\end{array}$ \\
\hline Uni - EPP & 16.03 & $10.4(-1.9)$ & 5.33 & $-6.1(-4.4)$ & 1.62 & $0.6(-3.5)$ \\
\hline Tri - EPP & 16.82 & $15.8(2.9)$ & 5.16 & $-9.2(-7.4)$ & 1.57 & $-2.5(-6.4)$ \\
\hline Uni - EST & 15.71 & $8.2(-3.9)$ & 4.93 & $-13.2(-11.6)$ & 1.57 & $-2.5(-6.5)$ \\
\hline Tri - EST & 16.71 & $15.1(2.2)$ & 5.02 & $-11.6(-10.0)$ & 1.43 & $-11.2(-14.5)$ \\
\hline Uni - MML & 14.79 & $1.8(-9.6)$ & 4.32 & $-24.0(-22.6)$ & 1.20 & $-25.5(-28.5)$ \\
\hline Tri - MML & 14.93 & $2.8(-8.7)$ & 3.97 & $-30.1(-28.9)$ & 1.24 & $-23.0(-26.2)$ \\
\hline APO-Displ-EPP & 16.48 & $13.5(0.8)$ & 5.17 & $-9.0(-7.3)$ & 1.58 & $-1.9(-5.7)$ \\
\hline APO-Force-EPP & 16.48 & $13.5(0.9)$ & 5.19 & $-8.6(-7.1)$ & 1.58 & $-1.9(-5.6)$ \\
\hline APO-Displ-EST & 16.42 & $13.1(0.5)$ & 5.09 & $-10.4(-8.8)$ & 1.55 & $-3.7(-7.5)$ \\
\hline APO-Force-EST & 16.46 & $13.4(0.7)$ & 5.16 & $-9.2(-7.5)$ & 1.57 & $-2.5(-6.1)$ \\
\hline APO-Displ-MML & 15.52 & $6.1(-5.1)$ & 4.57 & $-19.6(-18.1)$ & 1.37 & $-15.0(-18.3)$ \\
\hline APO-Force-MML & 14.43 & $-0.6(-11.7)$ & 4.06 & $-28.5(-27.2)$ & 1.20 & $-25.4(-28.2)$ \\
\hline
\end{tabular}

* Error with respect to the experiment is unbracketed, and error with respect to NLTHA prediction is provided in brackets.

Table 5.Comparison of responses predicted by NLTHA, SPO2IDA and N2 with the RC building experiment

\begin{tabular}{cccccccc}
\hline $\begin{array}{c}\text { Analysis } \\
\text { Methods }\end{array}$ & $\begin{array}{c}\mathbf{S}_{\mathbf{a}} \\
\left(\mathrm{m} / \mathrm{s}^{2}\right.\end{array}$ & $\begin{array}{c}\text { Error** } \\
(\%)\end{array}$ & $\begin{array}{c}\mathbf{S}_{\mathbf{d}} \\
(\mathrm{cm})\end{array}$ & $\begin{array}{c}\text { Error } \\
(\%)\end{array}$ & $\begin{array}{c}\text { ISD }_{\max } \\
(\%)\end{array}$ & $\begin{array}{c}\text { Error } \\
(\%)\end{array}$ \\
\hline Experiment & - & 1.38 & - & 4.83 & - & 0.80 & - \\
\hline $\boldsymbol{N L T H A}$ & - & 1.38 & -0.5 & 4.50 & -6.9 & 0.71 & -10.5 \\
\hline \multirow{2}{*}{ SPO2IDA } & Uni & $1.38^{*}$ & - & 3.67 & $-23.8(-18.4)$ & 0.60 & $-25.0(-15.5)$ \\
\cline { 2 - 8 }$(50 \%)$ & Tri & 1.38 & - & 4.45 & $-7.8(-1.1)$ & 0.67 & $-16.3(-5.6)$ \\
\hline \multirow{2}{*}{$\boldsymbol{N} \mathbf{2}$} & Uni & 1.44 & $3.7(4.2)$ & 4.19 & $-13.1(-6.9)$ & 0.69 & $-13.8(-2.8)$ \\
& Tri & 1.23 & $-11.3(-10.9)$ & 4.60 & $-4.7(2.2)$ & 0.76 & $-4.9(7.0)$ \\
\hline
\end{tabular}

* The $\mathrm{S}_{\mathrm{a}}$ value used for SPO2IDA corresponds to the value obtained from the performance point of the experiment. ** Error with respect to the experiment is unbracketed, and error with respect to NLTHA prediction is provided in brackets.

Table 6.Comparison of responses predicted by FRACAS using several pushover curves and capacity curve idealisations, with the RC building experiment

\begin{tabular}{|c|c|c|c|c|c|c|}
\hline $\begin{array}{l}\text { Analysis } \\
\text { Methods }\end{array}$ & $\begin{array}{c}\mathbf{S}_{\mathbf{a}} \\
\left(\mathrm{m} / \mathrm{s}^{2}\right)\end{array}$ & $\begin{array}{c}\text { Error* } \\
(\%)\end{array}$ & $\begin{array}{c}\mathbf{S}_{\mathbf{d}} \\
(\mathrm{cm})\end{array}$ & $\begin{array}{c}\text { Error } \\
(\%)\end{array}$ & $\begin{array}{c}\text { ISD }_{\max } \\
(\%)\end{array}$ & $\begin{array}{c}\text { Error } \\
(\%)\end{array}$ \\
\hline Uni - EPP & 1.53 & $10.3(10.8)$ & 4.54 & $-5.9(0.9)$ & 0.76 & $-4.9(7.0)$ \\
\hline Tri - EPP & 1.44 & $4.2(4.7)$ & 4.93 & $2.2(9.6)$ & 0.74 & $-6.5(4.2)$ \\
\hline Uni - MML & 1.43 & $3.3(3.8)$ & 4.17 & $-13.7(-7.3)$ & 0.69 & $-13.8(-2.8)$ \\
\hline Tri - MML & 1.31 & $-5.0(-4.6)$ & 4.59 & $-5.0(2.0)$ & 0.71 & $-10.5(0.0)$ \\
\hline APO-ISD-EPP & 1.48 & $7.0(7.5)$ & 4.49 & $-6.9(-0.2)$ & 0.67 & $-16.2(-5.6)$ \\
\hline APO-Displ.-EPP & 1.51 & $9.3(9.8)$ & 4.39 & $-8.9(-2.4)$ & 0.68 & $-14.3(-4.2)$ \\
\hline APO-Force-EPP & 1.50 & $8.5(9.0)$ & 4.58 & $-5.1(1.8)$ & 0.76 & $-4.9(7.0)$ \\
\hline APO-ISD-MML & 1.48 & $7.1(7.6)$ & 4.49 & $-6.9(-0.2)$ & 0.67 & $-16.2(-5.6)$ \\
\hline APO-Displ-MML & 1.45 & $4.6(5.1)$ & 4.19 & $-13.1(-6.9)$ & 0.65 & $-18.1(-8.5)$ \\
\hline APO-Force-MML & 1.44 & $4.3(4.8)$ & 4.94 & $2.4(9.8)$ & 0.81 & $2.3(14.1)$ \\
\hline
\end{tabular}

* Error with respect to the experiment is unbracketed, and error with respect to NLTHA prediction is provided in brackets. 
All simplified methods are capable of producing adequate EDP (Top Drift, ISD $\mathrm{max}_{\max }$ ) estimations for regular structures. All three methods estimate ISD $_{\max }$ by converting the PP into coordinates on the original PO curves of the structure, and determining the $\mathrm{ISD}_{\max }$ to that point. In case of steel building, N2 method gives a significant overestimation of $\mathrm{ISD}_{\max }$, ranging from $8.7 \%$ up to $12.4 \%$ for triangular and uniform PO respectively. In contrast SPO2IDA underestimates the $\mathrm{ISD}_{\max }$ values, namely $2.5 \%$ for Tri PO and $-7.5 \%$ for Uni PO. FRACAS produces a wide error range depending on its PO idealisation. Excluding the MML idealisation results that are also found to poorly predict the performance point, errors between $0.6 \%$ and $-11.2 \%$ are seen, with most idealisations resulting in errors less than $4 \%$.

With regard to the RC building, SPO2IDA produces the highest underestimation of $\mathrm{ISD}_{\max }$ (error reaching $-25 \%$ ), while the estimation errors for $\mathrm{N} 2$ are within an acceptable range (Tri: $-4.9 \%$ and $-13.8 \%$ ). Conventional PO combined with EPP idealisation models employed in FRACAS consistently produce good estimates of $\mathrm{ISD}_{\max }$. According to the outcome of the RC experiment, the structural failure occurred at the third floor, which is in agreement with the results obtained from NLTHA. FRACAS capabilities allow the user to obtain the ISD $_{\max }$ for each floor. In Figure 2 a representative conventional PO and an APO (namely Uni PO and Force based APO) analysis methods were selected for the EPP idealisation models to

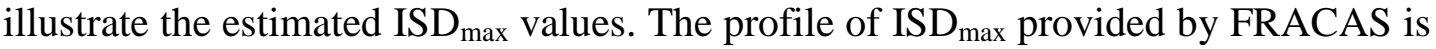
seen to generally match the experimental drifts but in some cases fails to identify the location of failure occurrence. For instance, the force based APO estimates the failure at the second floor (Figure 2).

- Experiment $\square$ NLTHA $\cong$ APO Force $\quad$ IIIUNI-PO

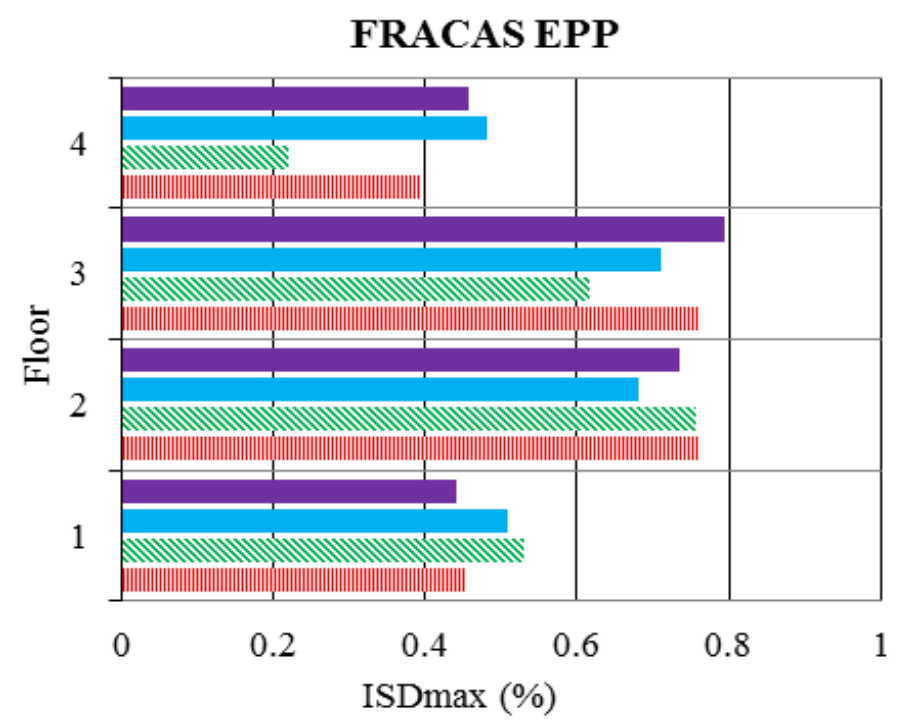

Figure 2.Comparison of $\operatorname{ISD}_{\max }(\%)$ measured at each floor of the RC building with predictions by NLTHA and FRACAS 


\section{CONCLUSION}

A comparison of three capacity spectrum assessment methods (N2, SPO2IDA and FRACAS) is carried out, highlighting the advantages and limitations of the approaches. The response predictions from each capacity spectrum approach and from NLTHA are compared for two case studies of published experiments on moment resisting frames. NLTHA generally provides the best estimate of the response parameters in both case study structures. However, NLTHA requires significant computational expense that often makes its use unfeasible in the derivation of fragility functions.

For the chosen case study, all three capacity spectrum approaches provide good estimates of the performance point coordinates $\left(S_{\mathrm{a}}-S_{\mathrm{d}}\right)$ for the simple steel frame. This is to be expected as the steel frame is a simple, regular, low-rise structure with predominant first mode response, for which capacity spectrum approaches should be able to provide good estimates of response. Worse estimates of response result when the capacity spectrum approaches (and NLTHA) are applied to the irregular RC frame that tends to fail through a soft storey mechanism at its third floor. However, the EPP idealisation model of FRACAS is seen to outperform the other approaches, and comparison of the ISD max $_{\text {ax }}$ predicted by FRACAS at each storey of the structure with those from the experiment also shows good agreement.

Although slightly more computationally expensive than the other approaches, FRACAS is the only approach that can use selected accelerograms as the demand input, and allows more flexibility in modelling the capacity curve. However, further comparisons of the capacity spectrum assessment methods for various building typologies and associated experimental tests are required in order to draw robust conclusions. Furthermore, it is clear that the influence of capacity curve idealisation model choice, in the case of FRACAS, also requires further investigation.

\section{REFERENCES}

Campos-Costa A. and Pinto A.V., (1999). "European seismic hazard scenarios - an approach to the definition of input motions for testing and reliability assessment of civil engineering structures". Joint Research Center (JRC) Special Publication, JRC, Ispra, Italy.

Carvalho E.C., Coelho E. and Campos-Costa A., (1999). "Preparation of the fullscale tests on reinforced concrete frames. Characteristics of the test specimens, materials and testing conditions". Innovative Seismic Design Concepts for New and Existing Structures (ICONS) Report, European TMR Network LNEC, Lisbon, Portugal.

D’Ayala D., Meslem A., Vamvatsikos D., Porter K., Rossetto T., Crowley H., Silva V., (2013), "Guidelines for Analytical Vulnerability Assessment Vulnerability Global Component project", Available from: www.nexus.globalquakemodel.org/GEM_VULNERABILITY_PHYSICAL/p osts/ 
D’Ayala. D., Meslem. A., Vamvatsikos, D. (2014), "Guidelines for the generation of analytical fragility functions for low- to mid-rise buildings", GEM Technical Report 2013-X, GEM Foundation, Pavia, Italy.

European Committee for Standardization (CEN), (2004). EN 1998-1:2004, Eurocode 8: Design of structures for earthquake resistance.

Faella C., Lima C. and Martinelli E., (2008), "Non-Linear Static Methods for Seismic Fragility Analysis and Reliability Evaluation of Existing Structures", The $14^{\text {th }}$ World Conference on Earthquake Engineering, China.

Fajfar P., (2000), "A nonlinear analyzes method for performance based seismic design", Earthquake Spectra, 16(3), pp. 573-592.

FEMA P-58 (2012). Seismic performance assessment of buildings. Prepared by Applied Technology Council as ATC 58. Prepared for Federal Emergency Management Agency. Washington D.C.

Gehl, P., Douglas, J., Rossetto, T., Macabuag, J., Nassirpour, A., Minas, S., Duffour, P. (2014). "Investigating the use of record-to-record variability in static capacity spectrum approaches". Second International Conference on Vulnerability and Risk Analysis and Management (ICVRAM2014) \& Sixth International Symposium on Uncertainty Modelling and Analysis (ISUMA2014). 13-16 July, Liverpool, UK.

Kim S-E., Lee, D-H., Ngo-Huu, C. (2007). "Shaking table tests of a two-story unbraced steel frame", Journal of Constructional Steel Research, Volume 63, Issue 3, March 2007, pp. 412-421, ISSN 0143-974X

Pinho R. and Antoniou S., (2005), "A displacement-based adaptive pushover algorithm for assessment of vertically irregular frames.", Proceedings of the Fourth European Workshop on the Seismic Behaviour of Irregular and Complex Structures, Thessaloniki, Greece.

Pinto A., Verzeletti G., Molina J. and Varum H., (1999). "Pseudo-dynamic tests on non-seismic resisting RC frames (bare and selective retrofit frames).", Draft report for the European Commission 245 programme: Innovative Seismic Design Concepts for New and Existing Structures (ICONS), Joint Research Centre, Ispra, Italy.

Rossetto T. (2004), "Vulnerability Curves for the Seismic Assessment of Reinforced Concrete Structure Populations". PhD Thesis, Imperial College London, UK.

Rossetto T. and Elnashai A., (2005), "A new analytical procedure for the derivation of displacement-based vulnerability curves for populations of RC structures, Engineering Structures, 27, pp. 397-409, 2005.

SeismoSoft, (2007), "SeismoStruct: A computer program for static and dynamic nonlinear analyzes of framed structures" (online), available from URL: http://www.seismosoft.com.

Vamvatsikos D. and Cornell A., (2006), "Direct estimation of the seismic demand and capacity of oscillators with multi-linear static pushovers through IDA", Earthquake Engineering and Structural Dynamics, 35(9), pp. 1097-1117.

Vamvatsikos D. and Cornell C.A., (2002), "Incremental Dynamic Analysis", Earthquake Engineering and Structural Dynamics, 31 (3), pp. 491-514. 